\title{
TIG Yöntemi ile Ostenitik Paslanmaz Çelik Yüzeyine Kaplanan Stellite 6+FeMo Tabakasının Mikroyapı ve Sertlik Ö̈zelikleri Üzerine Etkisinin İncelenmesi
}

\author{
Hüseyin TURHAN ${ }^{1}$, Niyazi Y1lmaz ÇOLAK ${ }^{2 *}$ \\ ${ }^{1}$ Fırat Üniversitesi Teknoloji Fak. Metalurji ve Malzeme Mühendisliği Böl., Elazı̆̆ \\ ${ }^{2}$ Bitlis Eren Üniversitesi Teknik Bilimler MYO., Bitlis
}

\begin{abstract}
Öz
Bu çalışmada, AISI 304 östenitik paslanmaz çelik yüzeyi Tungsten Inert Gas (TIG) kaynak yöntemi kullanılarak Stellite 6+FeMo alaşımı ile kaplanmıştır. Kaplanan tabakanın mikro yapısı, optik mikroskop (OM), taramalı elektron mikroskobu (SEM) ile incelenip yoğun enerjili X ışını analizi (EDS) ile analiz edilmiştir. Ayrıca numunelerin sertlik dağılımları mikro ve makro sertlik ölçümleri ile değerlendirilmiştir. Optik mikroskop ve mikroyapı incelemeleri neticesinde, kaplama tabakası ile alt tabakanın birbirlerine bağlandığı, kaplamada FeMo tozu ilavesine bağlı olarak sertlik değerlerinin arttığı ve tane sınırlarında ince taneli dentritik yapıların meydana geldiği tespit edilmiştir. Yüzey kaplama işlemi ile altlık metale göre daha sert ve dolayısıyla dış etkilere karşı daha mukavemetli bir yüzey tabakası elde edilmiştir.
\end{abstract}

Anahtar kelimeler: AISI 304, Stellite 6, FeMo, TIG, Yüzey Kaplama.

\section{Investigation of Microstructure and Hardness Properties of Stellite 6+FeMo Layer Which is Coated on Austenitic Stainless Steel Surface Using the TIG Method}

\section{Abstract}

In this study, AISI 304 austenitic stainless steel surface is coated with Stellite 6+FeMo alloy using Tungsten Inert Gas (TIG) welding method. The microstructure of the coated layer was examined by optical microscopy (OM) and scanning electron microscopy (SEM), and it was analyzed using the intense energetic X-ray analysis (EDS). In addition, the hardness distributions of the samples were evaluated by micro and macro hardness measurements. As a result of optical microscope and microstructure analyses, it was determined that hardness values increased and fine-grained dendritic structures were observed at grain boundaries due to the addition of FeMo powder to the coating layer and the lower layer to which the coating layer and the lower layer were bonded. As a result of the surface coating process, a surface layer which is harder than the base metal and therefore more resistant to external influences has been obtained.
\end{abstract}

Keywords: AISI 304, Stellite 6, FeMo, TIG, Surface Coating.

\section{Giriş}

Yüzey mühendisliği, malzemelerin yüzey özelliklerini geliştirmek için özellikle; sürtünmenin olduğu makina parçalarında meydana gelen aşınma problemlerini azaltmak, metal parçaların ve takımların yüzeylerinde üstün mekanik özellikler ve fonksiyonellik elde etmek amacı ile yapılan yüzey işlemlerini ve sert kaplama yöntemlerini kapsar[1]. Yüzey kaplama, kaynak yöntemleri kullanılarak altlık metalinden farklı kimyasal bileşim ve özelikteki metal veya metal alaşımlarının yeni bir yüzey tabakası oluşturmak amacı ile altık metal yüzeyine kaplanması işlemidir. Yüzey kaplama işlemi darbe, aşınma, yıpranma, erozyon ve oyulmayı azaltmak ve yüzey özelliklerini geliştirmek için orijinal parçalara uygulandığı gibi hasar gören parçaların tamiri içinde uygulanır [2]. Farklı metal altlıklar üzerine yapılan

\footnotetext{
*Sorumlu yazar: nycolak@beu.edu.tr

Geliş Tarihi: 16/02/2018 Kabul Tarihi: 06/03/2018
} 
kaplamalar, son yıllarda petrokimya, otomotiv ve uzay teknolojisi alanlarında etkin olarak kullanılmaktadır [3].

GTA yöntemi ile yüzey modifikasyonu işleminde, çeşitli tozlar kullanılarak istenilen bileşim ve oranlarda, alt tabakadan farklı özelliklere sahip bir kaplama tabakası oluşturulur. Ergime, altlık malzemesi ve kaplama malzemesinde aynı anda oluşur ve hızlı katılaşma ile kaplama katı ve altlık metal metalurjik olarak birleşir. Yöntemde genel olarak hızlı bir katılaşma görülmektedir. Hızlı katılaşma sonucu sert karbür fazlarını içeren ince taneli mikroyapılar meydana gelir ve bu yapılar yüzeyde sertlik, aşınma direnci vb. özelliklerde gelişmelere neden olur. İyi kaynak özellikleri, ark bölgesinin bir soy gazla korunması gibi özellikleri nedeniyle, GTA yöntemi aşınma uygulamalarında ve sertlik istenen durumlarda mikroyapı özelliklerinin değiştirilmesinde kullanılmaktadır [4,5].

Östenitik çeliklerin aşınma dirençlerinin yükseltilebilmesi matriste sert karbürlerin homojen bir şekilde dağılmalarıyla mümkündür. Bu çelik türleri, yer altı çalışmalarında kullanılan teçhizatlar, greyderler, ögütücü değirmen astarları gibi ileri derecede aşınmaya maruz kalabilen yerlerde kullanılırlar [6]. Östenitik paslanmaz çelikler korozyon dirençleri sebebi ile nemli ortamlarda tercih eden bir malzemedir. Östenitik paslanmaz çeliklerin alaşımındaki krom $(\mathrm{Cr})$ ve molibden $(\mathrm{Mo})$ miktarındaki artış ile agresif çözeltilere karşı korozyon direncinin arttırılmasını sağlamaktadır. Östenitik paslanmaz çeliklerde bileşimdeki molibden ve krom miktarının artışına paralel olarak çukurcuk ve aralık korozyonlarına karşı dirençleri de artmaktadır [7].

Kobalt esaslı alaşımlar aşınma uygulamalarında yaygın olarak kullanılmaktadır. Hareketli makine parçalarında yüzeylerin aşınmaya karşı dirençli olması istenilir. Bu sebeple yapılan araştırmalar, aşınmaya karşı daha dirençli olan kobalt esaslı alaşımların geliştirilmesine neden olmuştur. Kobalt esaslı sert kaplama alaşımları "Stellite'ler" olarak bilinir. Stellite alaşımlarının kullanımı, hamur ve kâğıt işleme, petrol ve gaz işleme, ilaçlar, kimyasal işleme gibi çeşitli endüstriyel sektörlere yayılmış ve stellite alaşımlarının geliştirilmesi ihtiyacı artmıştır. Kobalt esaslı stellite alaşımları sert dolgu malzemesi olarak kullanılmakla birlikte yüksek sıcaklık, yüksek basınç ve yüksek aşınma direnç ide göstermektedir. Farklı stellite alaşımları arasında endüstride en yaygın kullanılan stellite 6 alaşımının yaklaşık bileşimi Co- 28Cr-4.5W-1.1C (\% Ağırlık) dur [8-9].

Stellite 6, karbürler alaşıma güç katarken kromun korozyon direnci sağladığı, kullanışlı bir sertleştirici alaşımdır. Alaşımda Molibden (Mo) ve tungsten (W) katı eriyik sertleştirmesi sağlarken Kobalt (Co) metaller arası fazların oluşması ile çökeltme sertleştirmesi yoluyla Stellite 6' nın mukavemetine katkıda bulunurlar. Stellit kaplamalar paslanmaz çelikler üzerine metal ark (MMA), tungsten inert gaz (TIG) ve oksi-asetilen, lazer gibi değişik kaynak teknikleri kullanarak yapılmaktadır [10-11-12]. Shin ve ark.[13], kobalt esaslı Stellite alaşımında molibden miktarının mikroyapı özellikleri ve aşınma davranışı üzerine etkisini incelemişlerdir. Yapılan çalışmada molibden miktarındaki artış ile M23C6 ve M6C karbürleri kromca zengin M7C3 karbürlerinin yerinde oluşmuş ve M23C6 tip karbürleri ise serbest halde bulunan molibden dendritleri arası alanda görülmüştür. Kromca zengin karbürler dendritler arası alanda azalır iken, M6C tipi karbürlerin bu kısımda arttığını tespit etmişlerdir. Kuzucu ve ark.[14], Stellite 6 alaşımına ağırlıkça \%6 Mo ilavesi ile kromca zengin karbür fazının interdendritik bölgelerde tabakalardan taneli şekle dönüştüğünü ve karbürlerin M7C3'den M23C6'ya dönüştügünü bildirmişlerdir.

Günümüzde, metal yüzeylerinin kullanım alanlarına bağlı olarak maruz kaldıkları korozyon, yorulma, sürtünme ve aşınmalara karşı dirençli olması istenir, bu sebep ile yüzey kaplama araştırmalarına duyulan ihtiyaç her geçen gün daha da artmaktadır [15]. Bilindiği gibi, kobalt bazlı alaşım Stellite 6'nın nominal kimyasal bileşimi; kobalt, krom ve tungsten gibi elementlerden oluşmuştur. Stellite 6 alaşımı na FeMo katkısının kaplama özellikleri üzerine etkisi bu çalışmanın odak noktası olmuştur. Stellite 6+FeMo alaşımıyla önemli bir endüstriyel malzeme olarak kullanılan AISI 304 östenitik paslanmaz çeliğin yüzeyi TIG kaynak yöntemi kullanılarak kaplama işlemi yapılmış ve yüzeyde oluşturulan kaplama tabakasının mikroyapı ve sertliği üzerine FeMo'nin etkileri araştırılmıştır.

\section{Materyal ve Metot}

Yapılan çalışmada, kimyasal bileşimleri Tablo 1'de verilen; altlık malzemesi AISI 304 östenitik paslanmaz çelik, kaplama malzemesi olarak Stellite 6 süper alaşımı ve tane boyutu $50 \mu \mathrm{m}$ olan FeMo 
toz kullanılmıştır. Altlık malzemesi AISI 304 östenitik paslanmaz çelik plaka $100 * 20 * 10 \mathrm{~mm}$ ölçülerinde kesilmiş ve Şekil 1'de görüldüğü gibi $1,5 \mathrm{~mm}$ derinlikte ve $5 \mathrm{~mm}$ genişlikte kanallar açılmıştır.

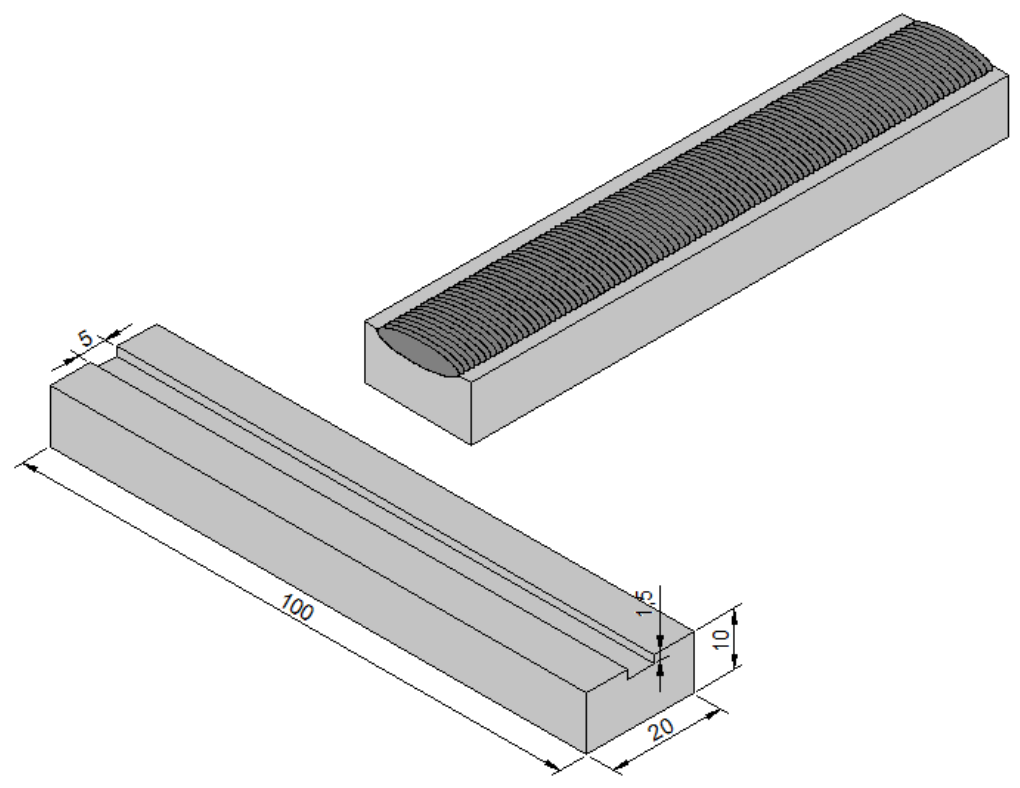

Şekil 1. Kaplama alt malzemesi boyutları

Kaplama tabakası için; kullanılan Stellite 6 alaşımı ağırlıç̧a \%20 FeMo toz ile alkol yardımıyla sıvanmış ve belli süre 1sıtılıp oluşturulan yeni alaşımdan alkol buharlaştırılmıştır. Şekil 2'de şematik resmi verilen TIG kaynak yöntemi ile belirlenen işlem parametrelerinde AISI 304 yüzeyine kaplanmıştır. Kaplama işleminde kullanılan parametreler Tablo 3 'te verilmiştir. Stellite 6+FeMo alaşım malzemesi, AISI 304 östenitik paslanmaz çelik yüzeyine 140A akım şiddetinde ve koruyucu argon gaz atmosferinde kaplama işlemi gerçekleştirilmiştir.

Tablo 1. AISI 304 ve Stellite-6 alaşımı ve FeMo kimyasal bileşimi(\% Ağırlık).

\begin{tabular}{cccccccccccc}
\hline Malzeme & Fe & C & Cr & Ni & Si & Mn & Co & W & S & P & Mo \\
\hline AISI 304 & 82.6 & 0.04 & 16.02 & 0.22 & 0.44 & 0.61 & - & - & - & - & - \\
\hline Stellite-6 & 2.50 & 1.44 & 30.46 & 2.92 & - & - & 34.15 & 15.71 & - & - & - \\
\hline FeMo & Bal & - & - & - & 0,5 & - & - & - & 0,03 & 0,03 & 80 \\
\hline
\end{tabular}




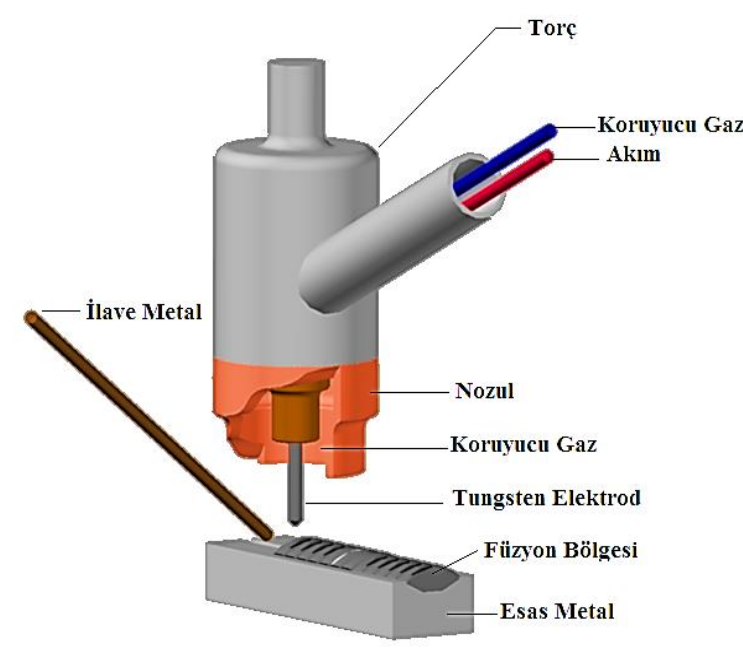

Şekil 2. TIG yöntemiyle yapılan kaplama işleminin şematik görünümü.
Tablo 3. Yüzey kaplama işlemi üretim parametreleri.

\begin{tabular}{ll}
\hline Numune No & FeMo + Stellite 6 \\
\hline FeMo Toz Miktarı & 1.408 \\
\hline İlave tel çapı & 3.2 \\
\hline İlave tel & Stellite-6 \\
\hline Kaplama Boyu & 100 \\
\hline Akım (A) & 140 \\
\hline Volt & 25 \\
\hline Isı Girdisi (J) & 20.208 \\
\hline Elektrod & $\% 2$ toryumlu tungsten elektrod \\
\hline Koruyucu Gaz & $\% 99.9$ Saf Argon \\
\hline Gaz Akış(It/dak.) & 12 \\
\hline Elektrod (mm) & 2.4 \\
\hline
\end{tabular}

Enerji girdisi Q = U.I.60/(V.1000) formülü ile hesaplanmıştır.

Kaplanan parçadan kesilerek çıkarılan numuneler standart metalografik işlemler ile hazırlanmış ve $5 \mathrm{ml}$ $\mathrm{HNO}_{3}+5 \mathrm{ml} \mathrm{C}_{2} \mathrm{H}_{4} \mathrm{O}_{2}+20 \mathrm{ml} \mathrm{HCI}+5 \mathrm{ml} \mathrm{H}_{2} \mathrm{O}$ çözeltide $12 \mathrm{~V}$ ve 20 sn süre ile elektrolitik olarak dağlanmıştır. Mikroyapı analizleri; optik mikroskop, taramalı elektron mikroskobu (SEM), enerji dağılımlı spektograf (EDS) ile incelenmiştir. Mikro sertlik ölçümleri, 200 gr yük altında 10 sn. süre ve $0.1 \mathrm{~mm}$ aralıkla Vickers (HV) sertlik değerinde ölçülmüştür. Makro sertlik ölçümleri ise 40 gr yük altında $0.5 \mathrm{~mm}$ aralıkla Vickers sertlik değeri cinsinden ölçülmüştür.

\section{Sonuçlar ve Tartışma}

\subsection{Makroyapı}

Numuneye ait makroyüzey fotoğrafi Şekil 3'te verilmiştir. Makroyüzey fotoğrafi incelendiğinde; kaplama tabakasının hatlarının düzenli bir görünüme sahip olduğu, ergimenin kaplama hattı boyunca yeterince iyi gerçekleştiği, kaplama tabakasında hızlı soğumaya bağlı herhangi bir gözenek, çatlak ve kaynak kusuru oluşmadığı, dikiş yapısının düzgün bir krater yapısında olduğu tespit edilmiştir.

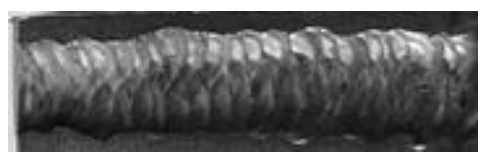

Şekil 3. Numuneye ait makroyüzey görüntüsü.

\subsection{Mikroyapı}

Stellite $6+$ FeMo alaşım malzemesi alaşım malzemesi ile kaplanan numuneden alınan yüzey ve arayüzey optik mikroskop görüntüleri Şekil $4 a-4 b$ 'de verilmiştir. TIG işlemi sonrasında kaplama tabakasının maksimum yüksekliğinin ortada oluştuğu kenar bölgelerinde ise kaplama kalınlığının inceldiği görülmüş̧ür. Bunun sebebini enerji yoğunluğunun elektrot ucuna dik olan doğrultuda daha yoğun şekilde meydana gelmesiyle açıklamak mümkündür. 

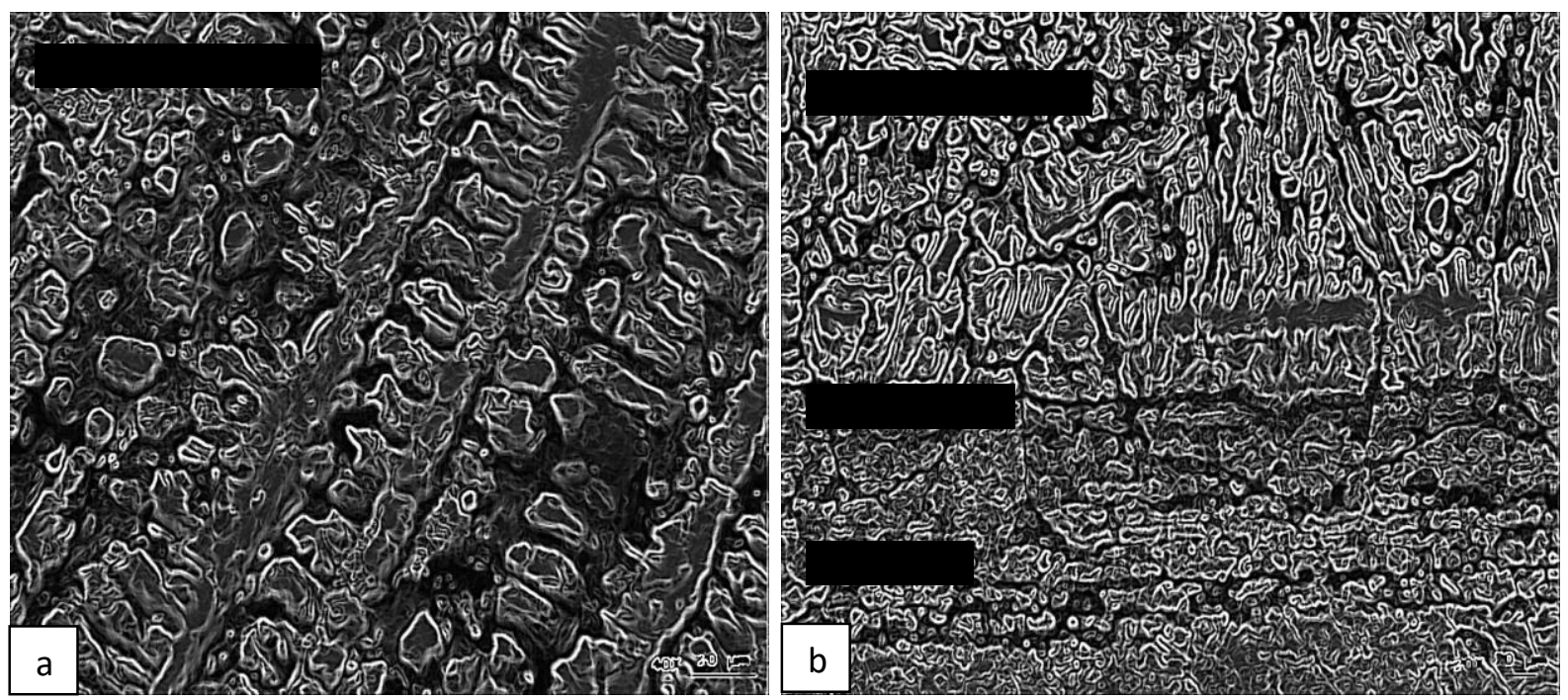

Şekil 4. Numuneye ait optik yüzey fotoğrafları a) Kaplama tabakası b) Kaplama-altlık metali ara geçiş bölgesi

Stellite 6+FeMo kaplama tozu kullanılarak GTA yöntemi ile yüzey modifikasyonu işlemine tabi tutulan numunenin yüzey modifikasyonu işleminden sonra kaplama yüzeyinden farklı büyütmelerde alınan SEM mikroyapı fotoğrafları Şekil 5-6'da sırasıyla verilmiştir. Kaplama esnasında oluşan 1sı tesiri neticesinde, ana malzemeden kaplama tabakasına, kaplama tabakasından da ana malzemeye difüzyonla geçişler Şekil 5'te görülmektedir İlave metalin miktarının az oluşu nedeniyle, birim ağırlığa isabet eden enerji miktarı artmış, kaplama katında ergime ve çözünme daha üst düzeyde gerçekleşmiştir. Dendritlerin birincil kolları oluşumlarını tam olarak sağlarken, kaplama ana metalin soğuk olması, dendritlerin ikincil kollarının belirgin bir şekilde oluşumlarını engellemiş ve hızlı soğuma sonucunda tabakalar arasında metal atomları geçişi sınırlı kalmıştır. Bu kaplamada ara tabaka belirgin bir şekilde seçilebilmektedir. Diğer yandan da ara geçiş bölgesi sınırları da belirginliğini kaybetmiş, dendrit kolları çoğalmış ve kalınlaşmıştır.

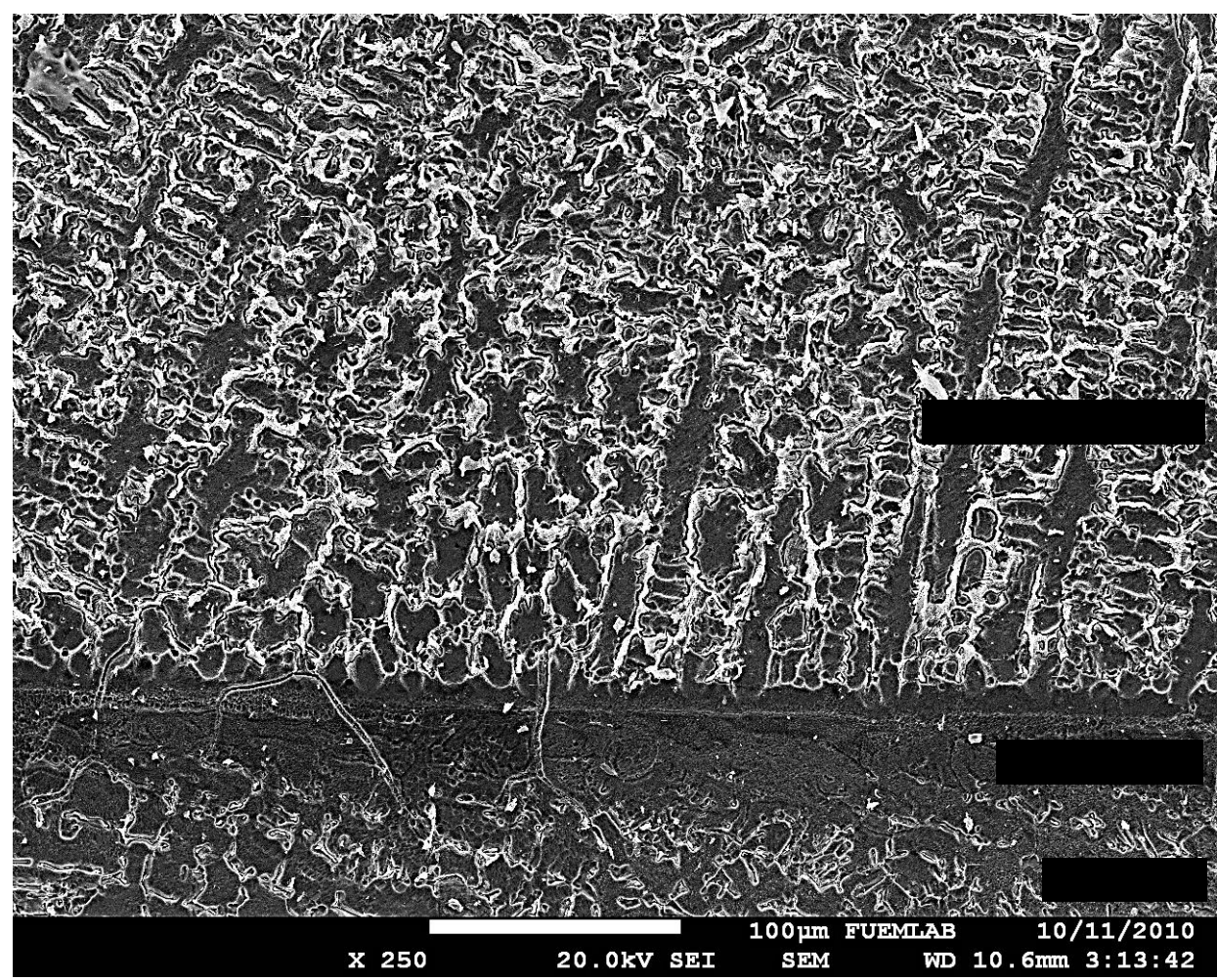

Şekil 5. Kaplama Tabakası ve Geçiş bölgesi SEM fotoğrafi (X250). 


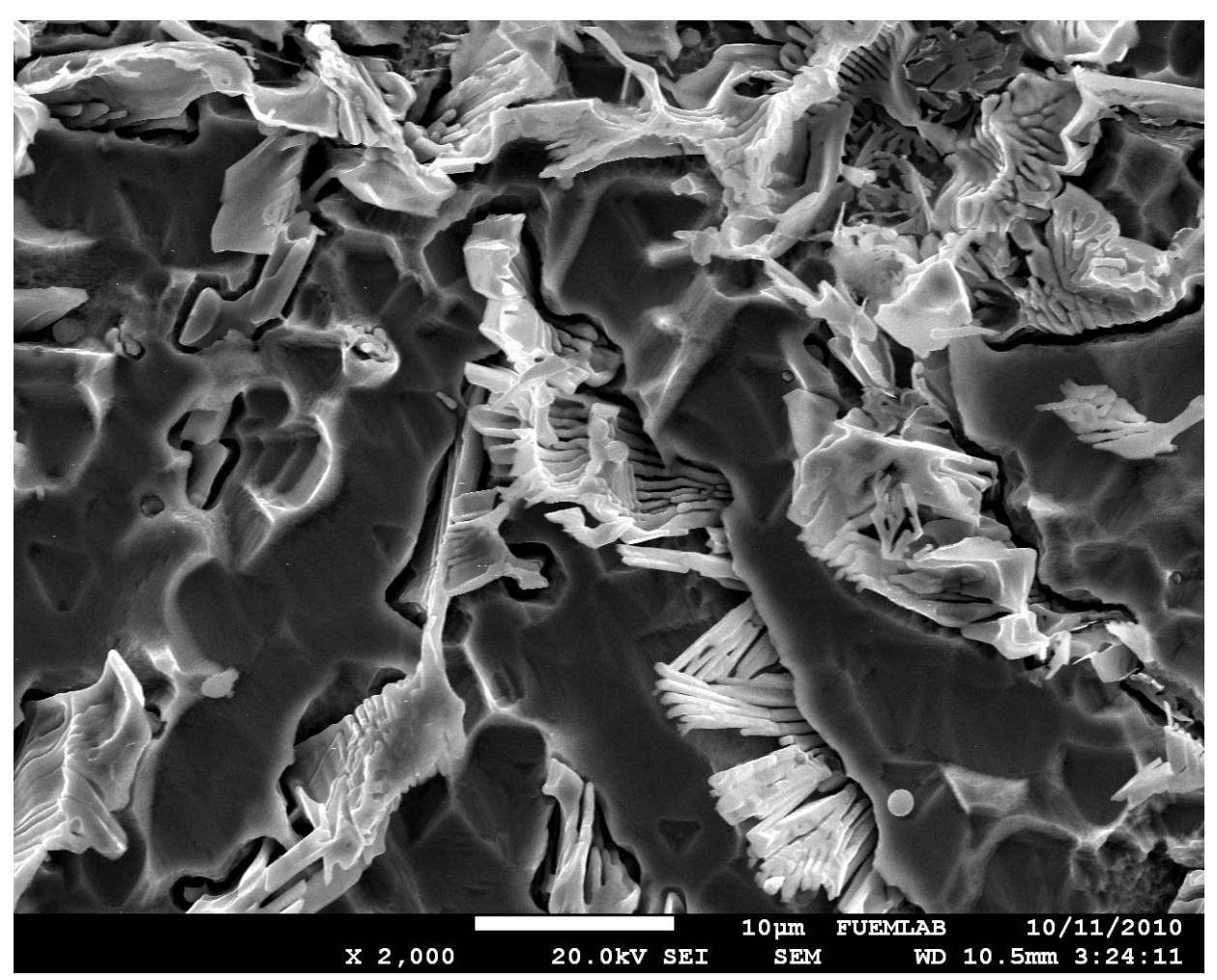

Şekil 6. Kaplama Tabakası SEM fotoğrafi (X2000).

\subsection{EDS Analizi}

Numuneye ait EDS analiz noktalarını gösterir SEM fotoğrafı Şekil 7'de verilmiştir. EDS analizleri için kaplama katı üzerinde dört farklı nokta seçilmiş ve noktaların matris ve karbürlere denk gelmesi istenmiştir. Deney numunesine ait EDS analiz grafiği ve analiz sonuçları Şekil 8-11'de verilmiştir. EDS analizleri değerlendirildiğinde 1 no'lu bölge altlık malzemesi üzerinden seçilmiş olup altlık malzeme içeriği olan $\mathrm{C}, \mathrm{Si}, \mathrm{Cr}, \mathrm{Mn}, \mathrm{Fe}, \mathrm{Ni}$, elementlerinin varlı̆̆ tespit edilmiştir. 2 no'lu bölge ara geçiş bölgesi üzerinden seçilmiş olup bu kısımda altlık malzemesi içeriği $\mathrm{C}, \mathrm{Si}, \mathrm{Cr}, \mathrm{Mn}, \mathrm{Fe}, \mathrm{Ni}$ ve ana kaplama alaşımının içeriği olan Co ve takviye malzemesi olarak kullanılan Mo'nin varlığ tespit edilmiştir. 3 no'lu bölge kaplama katından dendritler arası bölge üzerinden seçilmiş olup $\mathrm{C}, \mathrm{Si}, \mathrm{Cr}, \mathrm{Mn}, \mathrm{Fe}, \mathrm{Co}, \mathrm{Ni}$, Mo ve $\mathrm{W}$ tespit edilmiştir. Bu bölgede $\mathrm{Mn}$ ve $\mathrm{Si}$ altlık malzeme içeriği olduğundan altık malzemesinden takviye malzemesine geçişler olmuş ve ana kaplama alaşımının içeriği olan $\mathrm{Cr}$. Fe, Co ve W dendritler arası bölgeyi oluşturmuştur. 4 no'lu bölge kaplama katından dendrit üzerinden seçilmiş olup $\mathrm{C}, \mathrm{Si}, \mathrm{Cr}$, $\mathrm{Fe}, \mathrm{Co}, \mathrm{Ni}, \mathrm{Mo}, \mathrm{W}$ varlığı tespit edilmiştir.

Bu bölgede takviye olarak kullanılan Mo' nin dentritler üzerinde yoğunlaşarak difüze olduğu tespit edilmiştir. Stellite 6 alaşımı mikro yapısında kobaltça zengin dentrit kollarında W ve Cr karbürler ihtiva eder. Stellite 6 alaşımında, Cr, M7C3 ve M23C6 karbürlerin oluşmasıyla birlikte, oksidasyon, aşınma direnci ve mukavemet sağlar. Stellite alaşımlarının güçlendirilmesi için, refrakter elementler (tungsten veya molibden) ile katı eriyik sertleşmesine ve karbür çöktürmesine katkıda bulunurlar [16-17].

Kobalt esaslı alaşımların mikroyapılarında matris içine çökelmiş karbürlerin yanı sıra, intermetalik bileşikler de bulunabilir. Bu intermetalik bileşiklerin kararlılığı alaşımın bileşimine bağlıdır, Örneğin; $\% 20 \mathrm{Cr}$ 'lu Co-Cr-Ni sisteminde $1200^{\circ} \mathrm{C}$ 'nin üstünde intermetalik sigma fazı kararlı olmasına rağmen, \% $30 \mathrm{Cr}$ ' lu Co-Cr-Mo sisteminde bu faz ancak yüksek Mo içerikleri için düşük sıcaklıklarda kararlı olmaktadır. Bu da Mo' nin Ni'e kıyasla sigma fazını daha düşük sıcaklıklarda kararlı hale getirdiğini göstermektedir [18]. Dendritler daha yakın incelendiğinde (Şekil 7), dendrit kollarının kromca zengin krom karbürlerden, dendrit kolları arasında kalan noktaların da demirce zengin karbürlerden oluştuğu belirlenmiştir. $\mathrm{Bu}$ mikroyapı fotoğraflarından da görüleceği gibi yapının $\mathrm{Fe}$ ve $\mathrm{Cr}$ 'ca zengin dendritlerden oluştuğu görülmektedir. 


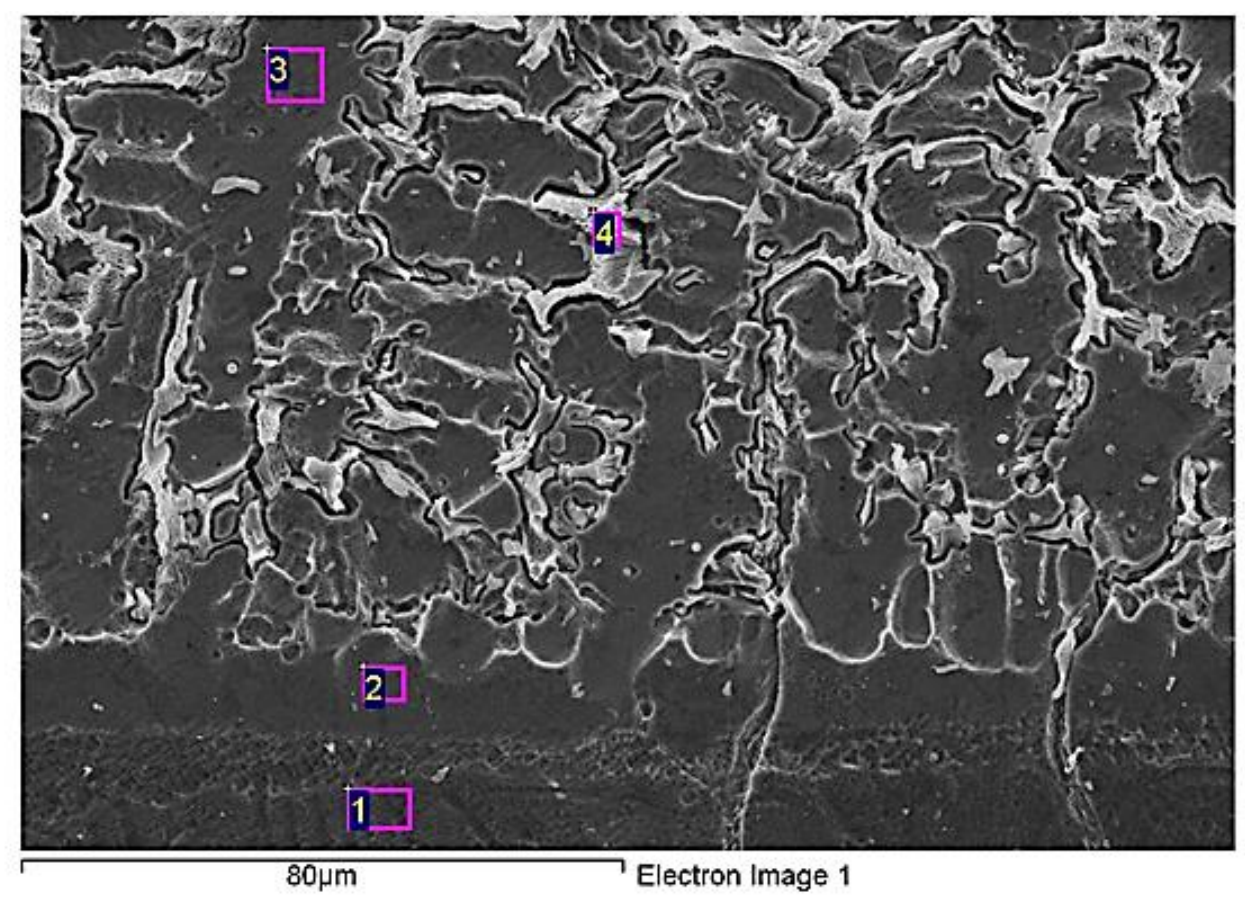

Şekil 7. EDS analiz bölgelerini gösteren SEM fotoğrafi.

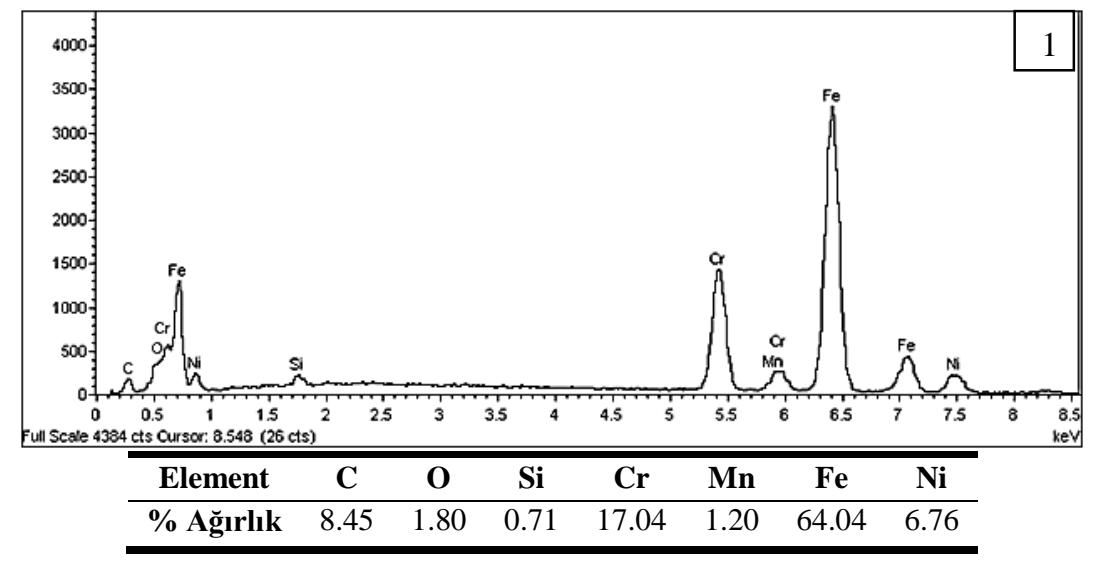

Şekil 8. 1 no’lu bölgeye ait EDS analiz grafiği ve EDS analiz sonuçları.

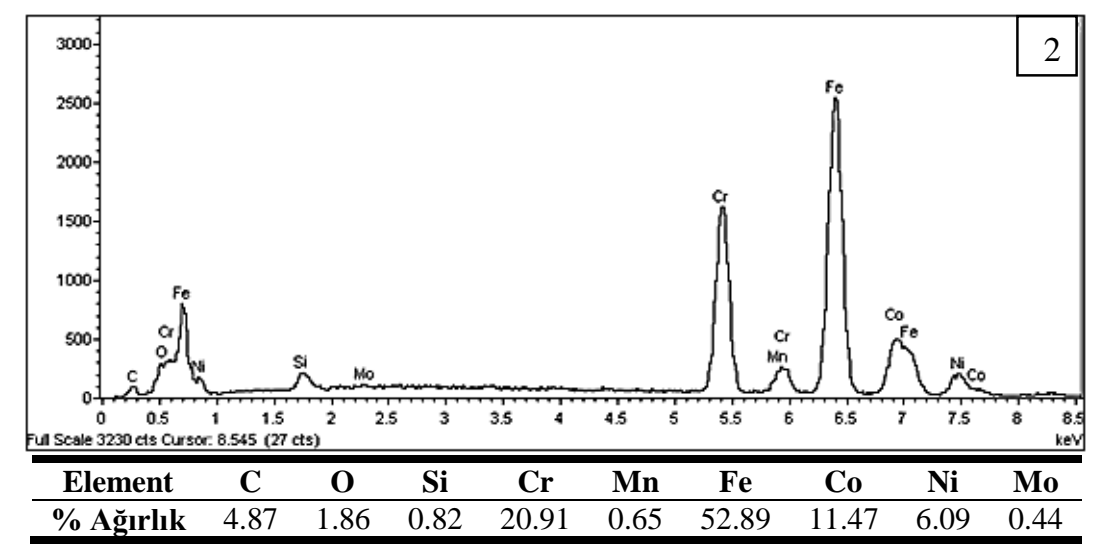

Şekil 9. 2 no'lu bölgeye ait EDS analiz grafiği ve EDS analiz sonuçları. 


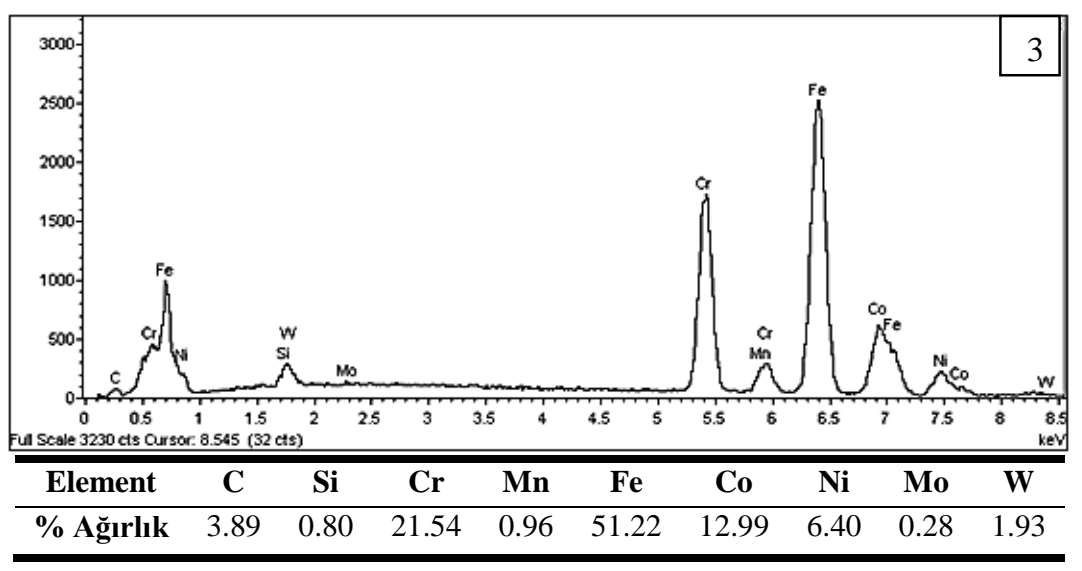

Şekil 10. 3 no'lu bölgeye ait EDS analiz grafiği ve EDS analiz sonuçları.

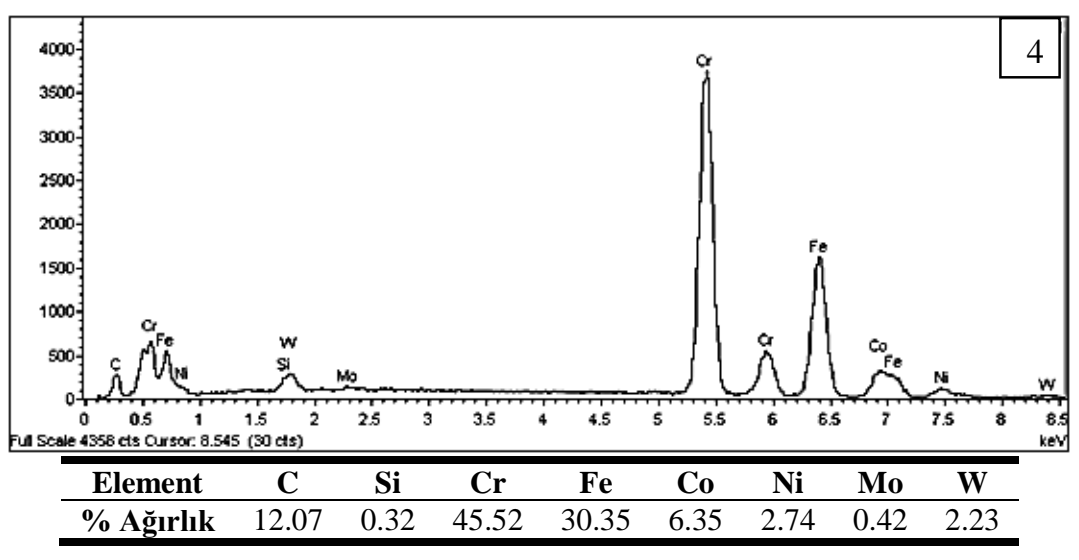

Şekil 11. 4 no'lu bölgeye ait EDS analiz grafiği ve EDS analiz sonuçları.

\subsection{Makro ve Mikrosertlik}

Tablo 4'de Stellite 6+FeMo ile kaplı numuneden alınan makro sertlik değerleri verilmiştir. Numuneye ait makro sertlik değerleri incelendiğinde ortalama sertlik değerlerinin 135 HV olduğu görülmüştür. Sertlik değerleri irdelendiğinde, Stellite 6 alaşımına ilave edilen FeMo sertlik değerlerinde artışa neden olmuştur. Kaplama katının hızlı soğuması ve ara yüzeye doğru yaklaştıkça yavaşlaması kaplama tabakasında ilk ve ani soğuyan uç kısımlarının sertliğini artırmıştır. Hızlı soğuma sonucu karbür miktarın da atış olmuş ve paralelinde sertlik değerleri de etkilenerek artmaktadır.

Tablo 4. Makrosertlik değerleri

\begin{tabular}{|c|c|c|}
\hline \multirow[t]{6}{*}{ Numune } & \multicolumn{2}{|c|}{ Makro Sertlik } \\
\hline & Stellite 6 & Stellite $6+\mathrm{FeMo}$ \\
\hline & 85 & 145 \\
\hline & 90 & 135 \\
\hline & 90 & 125 \\
\hline & 80 & 110 \\
\hline
\end{tabular}

Şekil 12'de mikrosertlik ölçüm sonuçları verilmiştir. Mikrosertlik değerleri incelendiğinde en yüksek sertlik 866 HV ölçülmüştür. Stellite 6 süper alaşımına FeMo ilavesi ile kaplama katında mikrosertlik değerleri artmıştır. Sertlik değerlerinin kaplama katmanına yaklaştıkça yükseldiği, geçiş bölgesinden itibaren yükselerek maksimum seviyelere ulaşmış ve hızlı bir düşüş göstererek altlık malzemenin sertlik değerine ulaşmıştır. Sertlik ölçümlerinde altlık malzemesinden kaplama katına yaklaştıkça difüzyon etkisi ve artan sert bileşiklerin oranına bağlı olarak sertlik değerleri hızlı yükselmiş ve geçiş bölgesinden kaplama tabakasının içerisinde de sertlik değerlerinin artmaya devam ettiği tespit edilmiştir. En yüksek 
setlik değerlerinin kaplama tabakasında alınmasının nedeni bu bölgede yoğun olarak bulunan karbürlerden kaynaklanmaktadır.

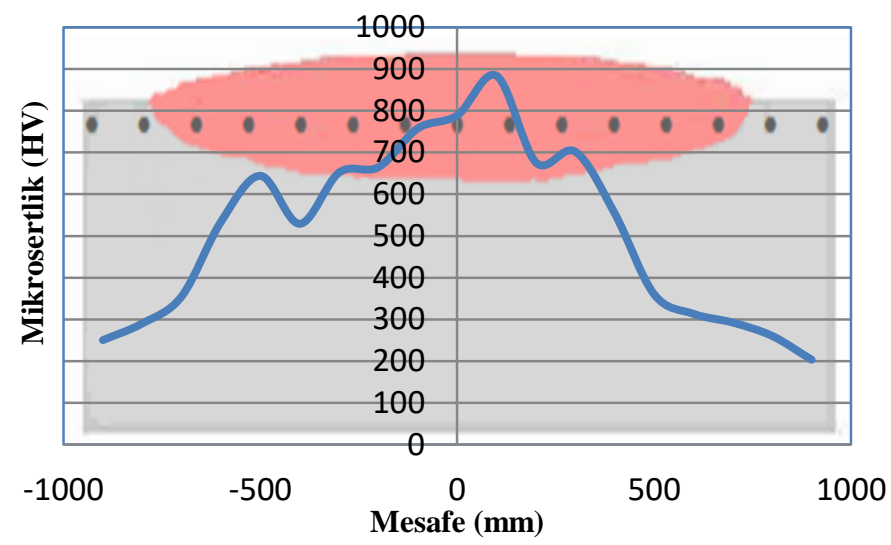

Şekil 12. Numuneye ait mikrosertlik değerleri.

Stellite alaşımlarının aşınma dirençlerini ve sertliklerini yüksek sıcaklıklarda da koruyabilmeleri önemli bir özelliğidir. Stellite alaşımlarının sertliğini yüksek sıcaklıklarda korumaları, bileşimlerindeki tungsten ve molibden miktarına bağlıdır [19].

\section{Sonuçlar}

TIG yöntemi kullanılarak, Stellite6+FeMo alaşımı ile yüzeyi kaplanan AISI 304 paslanmaz çeliğinin kaplama tabakasının, mikroyapı ve sertlik özelliklerinin incelendiği bu çalışmada elde edilen sonuçlar aşağıda belirtilmiştir.

1. Stellite 6+FeMo alaşımı, AISI 304 östenitik paslanmaz çelik yüzeyine normal atmosfer şartlarında herhangi bir önlem ve ön 1sıl işlemine gerek duyulmadan TIG kaynak yöntemi kullanılarak tek pasoda yüzeye kaplanmıştır.

2. Altlık malzemesi ile kaplama malzemesi, çatlak, topaklaşma olmadan ve gözeneksiz olarak kusursuz birleşmiştir.

3. Stellite 6 alaşımına ilave edilen FeMo ile kaplama tabakasında sertlik değerlerini artırmıştır. En yüksek mikro sertlik değerleri 866 HV ölçülürken En yüksek makro sertlik değerleri ise 145 HV olarak elde edilmiştir.

4. Kaplama mikro yapısında dendrit kolları net olarak görülmüş ve dendrit kol uzunluklarının yaklaşık aynı boyutlarda olduğu ayrıca dendrit kollarının kaplama sınır tabakasına doğru dikey olarak yönlendiği görülmüştür.

5. Stellite 6 alaşımına ilave edilen FeMo ile kaplanan AISI 304 östenitik paslanmaz çelik alaşımına FeMo'nin nüfuz ettiği ve ara geçiş bölgesine difüze olduğu görülmüştür.

6. Kaplamalarda dendritlerin birincil kolları oluşumlarını tam olarak sağlarken, kaplanan ana metal olan AISI 304 östenitik paslanmaz çeliğin soğuk olması, dendritlerin ikincil kollarının oluşumlarını belirgin bir şekilde engellemiş ve hızlı soğuma sonucunda tabakalar arasında metal atomları geçişlerinin sınırlı kaldığı gözlenmiştir. 


\section{Kaynaklar}

1. Saklakoğlu İ.E., Saklakoğlu N. 2004. Plazma Ortamına İyon Aşılama Yöntemi Genel Prensibleri ve Uygulama Alanları, Mühendis ve Makina Dergisi, Ocak Sayısı, 528.

2. Karataş M., Turhan H. 2012. Ostenitik Paslanmaz Çelik Yüzeyine GTA Yöntemiyle Alaşımlanan FeW+Stellite 6 Tabakasının Mikroyapı ve Sertlik Üzerine Etkisinin İncelenmesi, Firat University Journal of Engineering, 24 (2): 169-177.

3. Hidouci A., Pelletier J.M., Ducoin F., Dezert D., El Guerjouma R. 2000. Microstructural and mechanical characteristics of laser coatings, Surface and Coatings Technology, 123 (1): 17-23.

4. Çolak N.Y., Turhan H. 2016. AISI 304 Ostenitik Paslanmaz Çelik Yüzeyinin FeB+Stellite 6 Alaşımı Kullanılarak Yüzey Modifikasyonunun İncelenmesi, Makine Teknolojileri Elektronik Dergisi, 13 (1): $17-30$

5. Korkut M.H., Y1lmaz O., Buytoz S. 2002. Effect of aging on the Microstructure and Toughness of the İnterface Zone of a Gas Tungsten Arc (GTA) Synthesized Fe-Cr-Si-Mo-C Coated Low Carbon Steel, Surface and Coatings Technology, 157 (1): 5-13.

6. Güleç S., Aran A. 1987. Demir Dışı Metaller Malzeme Bilgisi, TÜBİTAK Yayını, 2: 123-235.

7. Kaluç E., Tülbentçi K. 1995. Paslanmaz Çelikler ve Kaynaklanabilirliği, Seminer Notları, Kocaeli Üniversitesi Kaynak Teknolojisi Araştırma, Eğitim ve Uygulama Merkezi, Kocaeli, 7-178.

8. Frenk A., Kurz W. 1994. Microstructural effects on the sliding wear resistance of a cobalt-based alloy, Wear, 174 (1-2): 81-91.

9. Malayoglu U., Neville A., Lovelock H. 2005. Assessing the Kinetics and Mechanisms of Corrosion of Cast and HIPed Stellite 6 in Aqueous Saline Environments, Corrosion science, 47 (8): 19111931.

10. Tiziani A., Giordano L., Matteazzi P., Badan B. 1987. Laser Stellite Coatings on Austenitic Stainless Steels, Materials Science and Engineering, 88: 171-175.

11. Jeshvaghani R.A., Shamanian M., Jaberzadeh M. 2011. Enhancement of Wear Resistance of Ductile İron Surface Alloyed by Stellite 6, Materials \& Design, 32 (4): 2028-2033.

12. Singh R., Kumar D., Mishra S.K., Tiwari S.K. 2014. Laser cladding of Stellite 6 on Stainless Steel to Enhance Solid Particle Erosion and Cavitation Resistance, Surface and Coatings Technology, 251: 87-97.

13. Shin J.C., Doh J.M., Yoon J.K., Lee D.Y., Kim, J.S. 2003. Effect of Molybdenum on the Microstructure and Wear Resistance of Cobalt-Base Stellite hardfacing Alloys, Surface and Coatings Technology, 166 (2-3): 117-126.

14. Kuzucu V., Ceylan M., Celik H., Aksoy I. 1997. Microstructure and Phase Analyses of Stellite 6 Plus 6 wt.\% Mo Alloy, Journal of Materials Processing Technology, 69 (1-3): 257-263.

15. Karataş M., Turhan H. 2011. The İnvestigation Surface Coating Using FeTi+Stellite 6 alloy of AlS1 304 Austenitic Stainless Steel Surface, e-Journal of New World Sciences Academy Engineering Sciences, 2A0070, 6 (4): 48-59

16. Farnia A., Ghaini F.M., Rao J.C., Ocelík V., De Hosson J.T.M. 2012. Effect of Ta on the Microstructure and Hardness of Stellite 6 Coating Deposited by Low Power Pulse Laser Treatments, Surface and Coatings Technology, 213: 278-284.

17. Radu I., Li D.Y. 2007. The Wear Performance of Yttrium-Modified Stellite 712 at Elevated Temperatures, Tribology International, 40 (2): 254-265.

18. Çelik H., Osman A., Çimenoğlu H., Kayalı E.S. 1995. Stellite 6 Alaşımının Yüksek Sicaklıktaki Aşınma Davranışına Silisyumun Etkisi, TMMOB Metalurji Müh. Odası, 8. Uluslararası Metalürji ve Malzeme Kongresi, İstanbul, 286-291.

19. Çelik H. 1991. Kaynak Edilebilen Kobalt ve Demir Esaslı Alaşımların Yüksek Sıcaklıklardaki Aşınma Davranışları, Doktora Tezi, İstanbul Teknik Üniversitesi, Fen Bilimleri Enstitüsü, İstanbul. 